\title{
A psicose ordinária e os fenômenos de corpo*
}

Márcia Rosa

Este artigo retoma as formulações lacanianas dos anos 50 sobre a psicose, psicose freudiana à la Schreber, e aquelas outras dos anos 1970, propostas a partir do sinthoma joyciano, de modo a discutir uma nova denominação surgida contemporaneamente, a psicose ordinária, e o modo como ela trata o corpo.

Palavras-chave: Psicose ordinária, corpo, clínica estrutural, clínica do sinthoma

* Este artigo faz parte de um trabalho de Pós-Doutorado (2007/2008) realizado no Programa de Pós-Graduação em Teoria Psicanalítica, Instituto de Psicologia da Universidade Federal do Rio de Janeiro - UFRJ, sob a orientação da Profa. Dra. Tânia Coelho dos Santos. 
Ao concluir uma de suas apresentações de enfermos, Lacan (1975a) endereçou-se aos presentes nos termos:

(...) alguns meses antes, examinei alguém que foi rotulado como um psicótico freudiano. Hoje vimos um psicótico lacaniano (...) muito claramente identificado. Com essas 'falas impostas', o imaginário, simbólico e o real". E, um pouco mais adiante, concluiu: "este é um quadro clássico, que não se encontrará descrito, mesmo por bons clínicos, (...). É para ser estudado. (p. 16)

Os termos através dos quais a psicose é adjetivada, "psicose freudiana", "psicose lacaniana" e "psicose clássica", tornam evidente que de um para outro teórico e clínico existem diferenças de concepção e, certamente, de orientações quanto à direção do tratamento. Além disso, podemos observar reformulações dentro de um mesmo corpo conceitual, tal como no campo lacaniano no qual temos o Lacan dos anos 1950, formalizando a psicose paranoica de Schreber, uma psicose freudiana, e o Lacan dos anos 1970, tomando a mão do artista James Joyce para tratar de outras manifestações da psicose, mais discretas. Se, no primeiro momento, a perspectiva estrutural colocava o clínico diante de quadros pensados de modo descontínuo, nos anos 1970 a descontinuidade entre os campos da psicose e da neurose se esfuma em benefício de uma localização do sujeito não em termos de classes, mas em relação a modos de amarração e de gozo particulares.

Ao levar em conta as manifestações contemporâneas da psicose e recolocar em discussão as leituras e formulações lacanianas sobre as psicoses, observamos o surgimento de uma nova adjetivação no campo da psicose, a "psicose ordinária". Tal denominação nasce da constatação de que:

(...) na história da psicanálise houve um interesse muito especial pelas psicoses extraordinárias, por gente que conseguia realmente um êxito ressonante. (...) enquanto que aqui temos psicóticos mais modestos, que reservam surpresas, mas que podem fundir-se em um tipo de média: a psicose compensada, a psicose suplementada, a psicose não-desencadeada, a psicose medicada, a psicose em terapia, a psicose em análise, a psi- 
cose que evolui, a psicose sinthomatizada - se me permitem. "A psicose joyciana é discreta, à diferença da obra de Joyce.” (Miller et al., 2005, p. 200)

Em vista disso, são essas manifestações incluídas sob o termo "psicose ordinária", manifestações que o discurso psiquiátrico tratou sob o termo de "psicose simples" ou "inespecífica", que tomaremos como tema de investigação no que se segue.

\section{A psicose ordinária}

O surgimento da denominação "psicose ordinária" se faz no contexto de um debate sobre a psicose proposto pelos psicanalistas associados ao Campo Freudiano, em conversações realizadas entre os anos de 1996 e 1998. Entre essas discussões, destaca-se aquela realizada em Arcachon (1997) sobre os casos raros ou inclassificáveis da clínica psicanalítica. De modo a contextualizar a questão temática em investigação, retomaremos alguns dos pontos levantados nessa conversação sobre os casos de difícil classificação.

\section{Os casos clássicos e os inclassificáveis ${ }^{1}$}

A experiência acumulada depois das primeiras elaborações de Lacan (19551956), no seminário sobre as psicoses e no texto "De uma questão preliminar a todo tratamento possível da psicose", e a experiência clínica contemporânea nos convidam a uma atualização, fundada na dialética entre a experiência clínica e os quadros conceituais e fundamentados pelos seminários apresentados por Lacan nos anos 1970: R.S.I. e $O$ sinthoma. Se tanto na neurose quanto na psicose temos um ponto de amarração do sujeito, em um caso essa amarração é feita pelo Nome-do-Pai e no outro ela pode ser feita por algo diferente e mais complexo, algo que Lacan representava pelos nós borromeanos e pelo sinthoma. Nos termos de Jacques Alain-Miller (1997), no primeiro caso temos o Lacan clássico, aquele do significante e do Nome-do-Pai, do objeto $a$ e do gozo e, no segundo, o Lacan do aparelho do sintoma.

1. Para os comentários feitos nesse item, retomo um texto publicado sob o título "Forclusão e fenômenos elementares”. Curinga, n.14, abr. 2000. São discutidas aí as formulações trazidas em Os casos raros, inclassificáveis da clínica psicanalítica. A conversação de Arcachon. São Paulo: Biblioteca Freudiana Brasileira, 1998. 
É importante anotar que a clínica dos aparelhos de sintoma, também dita clínica borromeana, não desconsidera a clínica do Nome-do-Pai, clínica estrutural, mas estabelece uma equivalência entre o sintoma e o Nome-do-Pai ( $\Sigma \cong$ N.P.) e relativiza o Nome-do-Pai, permitindo ver que ele não é nada mais do que um sintoma. Ao generalizar o Nome-do-Pai, esse novo sistema de atar possibilita uma mudança de perspectiva: se em uma clínica estrutural a psicose é abordada a partir do déficit significante, em uma clínica do sinthoma o Nome-do-Pai seria apenas uma das formas de atar. Teríamos, a partir daí, duas formas principais de amarração do sujeito: o Nome-do-Pai e o Sinthoma.

Partindo do pressuposto de que não há flutuação de uma estrutura a outra, de "que há estrutura, com sua lógica e seu tipo de sintoma, por vezes difíceis de serem revelados" (Miller, 1987, p. 119), interrogou-se, na Conversação de Arcachon, o que haveria de novo quanto a isso e em que pontos esse novo incidiriam: existiriam flutuações de uma estrutura a outra; existiriam novas lógicas e novos tipos de sintoma; existiria uma nova posição sobre a exigência de não recuar diante de um diagnóstico de estrutura ou um novo modo de estabelecer o diagnóstico?

Posto isso, uma das primeiras consequências a se extrair dessas discussões é uma relativização no que toca ao desencadeamento da psicose como determinado pelo encontro de Um - pai, ali onde o sujeito está deficitário em relação ao Nomedo-Pai pelo efeito da forclusão $\left(\mathrm{P}^{0}\right)$. Constata-se, por exemplo, em entidades como a mania, a melancolia etc., que os desencadeamentos nem sempre seguem essa lógica. Além disso, observa-se uma mudança de perspectiva concernente à questão diagnóstica. Os fenômenos elementares tomados no campo da linguagem mantêm-se como índices quanto ao diagnóstico, mas perdem o seu caráter de condição sine qua non.

Ao dizer ter tomado emprestado ao seu mestre em psiquiatria os termos "fenômenos elementares" e "automatismo mental", Lacan (1966) nos levou de volta à herança psiquiátrica da psicanálise. No seu entender, a análise estrutural aproximou-se da "ideologia mecanicista da metáfora" (p. 69-70) formulada pela psiquiatria francesa, com Clérambault. Partindo daí, ele (1955-56) mostra que o importante do fenômeno elementar não é ser um núcleo inicial em torno do qual o sujeito faria "uma reação fibrosa destinada a enquistá-lo" (p. 109-110), mas o seu caráter estrutural que mostraria, por exemplo, que o delírio é, ele também, um fenômeno elementar. Se o psiquiatra francês sustentava a sua assinatura clínica no caráter de automatismo daquilo que se apresentava, Lacan inovará ao localizar a riqueza da fenomenologia da psicose no registro da fala. Nesse sentido, se a experiência da psicose é um fio condutor no ensino do psicanalista francês, isso se deve, em princípio, ao fato "dos loucos demonstrarem - [exatamente no registro da linguagem] - a exterioridade do inconsciente" (Miller, 1987, p. 121). 
Formulados, de início, em uma terminologia psiquiátrica, os fenômenos elementares são apresentados por Jacques-Alain Miller (1988, p. 94-96) a partir de uma tripartição simples: o mental, o corporal e o que é da ordem da linguagem.

Os fenômenos de automatismo mental dizem daquilo que provém da influência externa sobre o sujeito - trata-se de um sentimento de que as coisas vêm de fora, ou seja, as palavras são escutadas e o pensamento também. Antes de serem formulados são comentados ou mesmo, em certos casos, impostos e, sem mediação, fazem-se ouvir em seu interior. Esses fenômenos - concernentes à irrupção de vozes e de discurso de outros na esfera psíquica mais íntima - são muito evidentes quando a psicose já se desencadeou, mas podem estar presentes, silenciosamente, durante anos com apenas uma ou duas irrupções na infância ou adolescência, ficando depois encobertos. Desse modo, o "automatismo mental" demonstra a exterioridade do inconsciente, consequência mesma da forclusão.

Existem também aqueles fenômenos que concernem ao corpo: fenômenos de decomposição, desmembramento, separação, e de estranheza em relação ao próprio corpo, ou de distorção temporal e de deslocamento espacial. Enfim, cabe considerar ainda os fenômenos que concernem ao sentido e à verdade, e que se manifestam, por exemplo, no testemunho por parte do paciente de experiências inefáveis, inexprimíveis, experiências de certeza absoluta e, ainda, no testemunho de experiências de significação pessoal, quando ele diz ler, no mundo, signos que trazem uma significação que lhe está destinada.

Abordando esses fenômenos em uma linguagem analítica, Miller (1988) diz que eles se referem aos registros do Real, Simbólico e Imaginário. Nesse sentido, pode-se dizer que há fenômenos elementares da ordem do Imaginário, os fenômenos corporais, da ordem do Simbólico, as vozes, as frases, aquilo que se relaciona com a linguagem, bem como aqueles que põem em evidência o Real, o caráter de certeza, por exemplo. "Para termos fenômenos elementares bem constituídos, digamos assim, são necessárias essas três vertentes dos fenômenos", afirma (ibid., 130-131). Isso posto, a conclusão dos anos 1950 é que para o diagnóstico de psicose não basta a presença dos fenômenos que concernem ao corpo ou ao sentido e à verdade. Lacan (1955-1956) propõe "que se adote, provisoriamente como convenção, que para que estejamos na psicose, é preciso haver distúrbios de linguagem", que "devemos exigir antes de dar o diagnóstico de psicose a presença desses distúrbios, dessas perturbações na ordem da linguagem (...)” (p. 109-110). A localização desses sinais é decisiva na medida em que eles são o atestado do ponto no qual aquilo que não foi simbolizado retorna no real, isto é, eles são os índices da forclusão.

Em frente às manifestações contemporâneas da psicose, as discussões de Arcachon evidenciaram a insuficiência dessas formulações lacanianas dos anos 1950. 
Em vista disso, ali aonde nos deparamos com formas clínicas mais ou menos inéditas, questões do tipo: "o que faz com que os três registros R.S.I se mantenham juntos aí?" ou "o que os agruparia?" nos orientariam melhor do que a questão: "Nome-do-Pai, sim ou não?". Nesse sentido, sinais de algo mal engatado, mal amarrado (frouxo) quanto aos três registros, por exemplo, "uma ligeira ancoragem simbólica, com pregnância do imaginário; uma relação de estranheza entre o eu e o corpo: uma desconexão da pulsão e da pegada do inconsciente" (Aflalo, 1998, p. 107) podem acabar constituindo um desses elementos que fazem o diagnóstico diferencial.

\section{A psicose ordinária}

Sob o termo "psicose ordinária" os participantes das conversações clínicas realizadas em Antibes (1998), sob o título A convenção de Antibes, incluíram a discussão de três pontos: o "novo desencadeamento", a "nova transferência" e a "nova conversão". ${ }^{2}$ Sob o primeiro termo examinaram as psicoses que não chegam a se desencadear, mas que manifestam momentos e movimentos de desligamento e de religamento do laço social; sob o termo "nova transferência" examinaram as vicissitudes dos laços sociais do sujeito psicótico e, finalmente, sob o termo "nova conversão" colocaram em discussão os fenômenos ligados ao corpo, abrindo um campo de intercessão entre a neurose histérica, o fenômeno psicossomático e os fenômenos corporais determinados pela ausência da significação fálica, também escritos $\Phi_{0}$.

Na medida em que é possível encontrar entre as classificações contemporâneas feitas pelo DSM-IV denominações como aquela de "transtorno dismórfico corporal" (2002, p. 488-491), ao recolocarmos a discussão dos fenômenos de corpo sob o termo "psicose ordinária" (Miller et al., 2005), encontraremos as assim denominadas "novas conversões". Se Lacan definiu a conversão como uma localização do desejo no corpo pela via do sintoma (ibid., p. 242), o uso do corpo nas "novas conversões" nos coloca diante de fenômenos não interpretáveis à maneira freudiana. Se no Lacan dos anos 1950 os fenômenos de corpo foram lidos, e tratados, a partir da significação fálica, encontraremos entre esses novos fenômenos de corpo uma relação entre o corpo e a linguagem que, deixando de lado o campo metafórico, nos confronta com uma escritura que nem sempre se dá a ler. Trata-se, então, de considerar os modos particulares de aparelhamento com o corpo, com o real pulsional e com a realidade dos órgãos. Se esses fenômenos não se

2. Conversação publicada sob o título La psicosis ordinária. 
amarram pela significação fálica, que tipo de amarração fazem entre o imaginário do corpo, os furos da linguagem e os fenômenos de gozo? (ibid., p. 247).

A partir disso, é possível colocar em pauta os vários usos possíveis do corpo: se para o esquizofrênico o corpo está fora-do-discurso, ele não será poupado do trabalho de encontrar um uso para os seus órgãos; já na histeria o corpo serviria ao desejo enquanto na neurose obsessiva ele estaria feito para servir e, ao mesmo tempo, recusar a demanda. Enfim, Miller (2005) observa que “(...) o uso do corpo no psicótico pode às vezes convergir com um uso que parece normal, ordinário, só que para chegar a isso ele deve fazer (...) um enorme esforço de invenção (...) enquanto para os neuróticos [o esforço] é de confecção" (ibid., 254-255).

\section{Caso clínico}

Um caso clínico, em cuja demanda e trabalho de análise o sintoma apresentou-se associado ao corpo e às suas singularidades, foi o responsável pelo meu interesse em trabalhar mais de perto a questão da psicose ordinária em sua articulação ao corpo. Ele me fez evocar a instigante expressão cunhada por Lacan (1975b): "o sintoma, um acontecimento de corpo" (p. 565). ${ }^{3}$

O caso desse jovem universitário nos permite particularizar a diferença existente entre os meninos e as meninas adolescentes em relação à forma de seus corpos: ali aonde as meninas têm horror de engordar (o que lhes vale a denominação de "falo magro" ou, mesmo, de "virgens magras"), os meninos têm uma espécie de horror de emagrecer: nada de falo magro! Não que eles queiram exatamente engordar, eles querem "ganhar peso, massa muscular". Ao ser mediada pelo falo, a relação ao próprio corpo parece trazer à cena a questão da tumescência e da detumescência e torna evidente que o despertar da sexualidade não é sem relação, e consequência, sobre o que se produz no campo sintomático. Tal é o caso desse jovem cuja magreza adolescente foi endereçada a um endocrinologista e tratada com um regime para engordar que, concluído com sucesso, deixou como resíduo uma compulsão a se pesar várias vezes por dia, de modo a se certificar de não ter perdido peso, possibilidade que o horroriza pelo sentimento de deflação narcisista associado. Sob o olhar de uma mãe depressiva, sempre vigilante e preocupada com a saúde do filho, esse sujeito constrói um quadro de anorexia mental no qual os objetos vão caindo sob o signo do nada: nada de namoradas! nada de amigos! nada

3. O termo em francês, "événement de corps", tem sido traduzido também pela expressão "evento corporal". 
de faculdade! nada...! nada...! A partir desse movimento de recusa ou de "desistência", ele vai produzindo "um jogo mórbido com a morte", nos seus próprios termos, jogo marcado pelo gozo da privação. O corpo mudou de forma, está musculado, mas o sujeito não o assimilou, não se apropriou dele, portanto não consegue se identificar com a nova imagem de si mesmo, com a nova forma de seu corpo, e tem dificuldades de operar com ele no registro da significação fálica, principalmente no jogo amoroso e sexual com as meninas. Até certo momento, a construção de laços e de parcerias é feita basicamente através desse gadget ${ }^{4}$ que é o PC. A Internet ocupa um lugar relevante para esse jovem sujeito, nela, além de sites ligados a videogames, ele encontra uma espécie de Serviço de Pronto-Atendimento que lhe permite ocupar as suas noites insones com um número imenso de postagens sobre suas questões subjetivas.

Alguns elementos fazem supor a vigência de um falo índice zero $\left(\Phi^{\circ}\right)$ e, portanto, de uma operação paterna inoperante $\left(\mathrm{P}^{0}\right)$. No entanto, embora vários elementos sugiram tratar-se de um sujeito não-neurótico, não temos aí um quadro de psicose classicamente delineado, ou seja, uma psicose marcada pela presença de fenômenos elementares no campo da linguagem, ou mesmo uma psicose desencadeada. Localizam-se, claramente, fenômenos ligados ao corpo em virtude de um não-reconhecimento ou identificação com o próprio corpo (legíveis como "acontecimentos de corpo"?), momentos de desligamento do Outro e do laço social e, na tentativa de uma estabilização, uma adesividade ou fixação em aparelhos (PC, videogames, guitarra, play-station etc.). Aparentemente legíveis pelo DSM-IV sob a denominação de "transtorno dismórfico corporal", 5 tais manifestações não deixam de nos levar ao campo disso que tem sido designado contemporaneamente como "psicose ordinária".

No que concerne aos caminhos da formação do sintoma, do sintoma na sua função de suplência em relação a uma operação paterna inoperante, trata-se de acompanhar, clinicamente, o modo como ele vai poder se valer (ou não) da "arte da qual ele é capaz" (Lacan, 1975-76, p. 59) no sentido de uma amarração sinthomática dos três registros corporais, a saber, imaginário (= imagem de si), simbó-

4. No seu texto "A terceira", Lacan se refere aos gadgets como a essas quinquilharias, esses objetos fabricados a partir da ciência, aos quais os sujeitos ficam fixados; por exemplo, o celular, o laptop, o videogame etc.

5. O DSM-IV caracteriza o "Transtorno Dismórfico Corporal" como "uma preocupação com um defeito na aparência". Esse defeito, imaginado ou construído a partir de uma ligeira anomalia física, é objeto de excessivas preocupações e causa sofrimento e prejuízo no funcionamento social e ocupacional. 
lico (= traços corporais com os quais se identifique e nos quais se reconheça) e real (= campo pulsional subjacente). O uso do th na grafia do sintoma neste momento indica que essa pequena invenção, essa arte da qual ele parece ser capaz, viria fazer função de suplência a uma operação paterna inoperante. Nesse sentido, é interessante observar que ele é talentoso no campo do desenho, no qual vem trabalhando em "tirinhas" ou "quadrinhos". A substituição da ideia de fazer um desenho com alguns personagens se embebedando em um cemitério, por uma outra na qual vários personagens fazem fila na porta de um consultório (desenho levado até a sessão de análise) atesta a presença da transferência e propicia alguns giros no caso em questão.

\section{Clínica do sinthoma}

O sintoma, definido por Lacan como um acontecimento corporal, abre uma questão segundo a qual a identificação com ele (principalmente aquela que ocorre no final de uma análise) pode ser concebida como uma identificação com o corpo. ${ }^{6}$ Nesse sentido, Lacan estabelece uma correspondência entre "a maneira como alguém se vira com seu sintoma" e o modo como ele se vira com sua imagem corporal. ${ }^{7}$ A partir disso, sob o termo "psicose ordinária" interessam em especial essas "novas conversões" através das quais enfoca-se o corpo e o modo como o sujeito se vira com ele.

Na sua "Conferência de Genebra sobre o sintoma" (4.10.1975), Lacan comenta:

(...) o homem é capturado pela imagem de seu corpo. Esse ponto explica muitas coisas e, de início, o privilégio que tem para ele a sua imagem. Seu mundo, (...) esse que há em torno dele, ele o corpo-reifica, ele o faz coisa à imagem de seu corpo. Ele não

6. Um comentário de Jacques Alain-Miller interessa-nos aqui. Diz ele: “(...) por ter sintomas é preciso 'ter' um corpo, não 'ser' um corpo, e que, para identificar-nos ao sintoma, é preciso ter um psicanalista. (...) O sintoma em estado natural, o sintoma que não é desnaturalizado por uma análise, é bem o que manifesta que não saberíamos identificar o homem com o seu corpo" (Miller, 2004, p. 50).

7. Segundo um comentário feito por Lacan em Lição de 16 de novembro de 1976, do seu seminário, L'insu que sait de l'une-bévue s'aile à mourre. Em francês lê-se: “Connaître son symptôme veut dire savoir faire avec, savoir le débrouiller, le manipuler. Ce que l'homme sait faire avec son image, correspond par quelque cote à cela, et permet d'imaginer la façon dont on se débrouille avec le symptôme”. 
tem a menor ideia, certamente, do que se passa em seu corpo. Como um corpo sobrevive? Não sei se isso surpreende vocês por pouco que seja - se vocês se fazem um arranhão, bem, isso se arranja. É tão surpreendente, nem mais nem menos, quanto o fato de que o lagarto que perde sua cauda a reconstitua. É exatamente da mesma ordem.

Tal comentário encontra suas ressonâncias no texto freudiano no qual é possível destacar as formulações dos anos 1916 e 1917, "O sentido dos sintomas" e "Os caminhos da formação do sintoma". Neste último, Freud (1917) observa que o sintoma despreza os objetos e busca satisfação no próprio corpo e não no mundo externo, o que tem como resultado a produção de modificações no corpo do sujeito (p. 428); ele acaba sentindo-se mal em sua própria pele. Embora Freud, ele próprio, tenha alertado sobre o fato de essas primeiras conferências sobre o sintoma não levarem em conta a distinção do psiquismo em eu, supereu e isso, nem a reformulação da teoria das pulsões dos anos 1920, é sobre elas que Lacan (4.10.1975) retorna em Genebra, associando o sentido (Sinn) dos sintomas à realidade sexual e estabelecendo uma distinção entre Sinn e Bedeutung, entre o sentido e a significação. "A significação é diferente de Sinn, do efeito de sentido, e designa a relação ao real" (Lacan, 4.10.1975), comenta ele, introduzindo no horizonte a questão do sentido e da referência tal como propostas por Gottlob Frege em seu texto "Sobre o sentido e a referência" (1892).

Ao nos reportarmos ao texto "Joyce, o sintoma", lemos: “(...) deixemos o sintoma no que ele é: um evento corporal [um acontecimento de corpo], ligado a que: a gente o tem, a gente tem ares de, a gente areja a partir do que a gente o tem" (Lacan, 1975b, p. 565). Em um outro texto da mesma época, Lacan (1974-75) traça os litorais da psicanálise na conexão com a religião, com a ciência e com a arte, que é nesse momento retomada através da presença de um escritor. A propósito, e ainda nesse mesmo ano de 1975, em uma conversa com os estudantes da Universidade de Yale, ele afirmara: "explicar a arte pelo inconsciente me parece o mais suspeito, é o que fazem os analistas. Explicar a arte pelo sintoma me parece mais sério" (24.11.1975, p. 35). Por ter tomado esta posição - metodológica, digamos assim - de explicar a arte pelo sintoma, o artista e a sua criação possibilitaram ao psicanalista o estabelecimento da via do sinthoma, agora grafado com o th de modo a indicar a sua função de amarrar os três registros I.S.R.: a consistência da imagem corporal (I), os furos "linguajeiros" do corpo do simbólico (S) e um exsistir do real (R), apresentado não apenas pela opacidade do real natural como também pela escritura marcada pelo gozo e pelo ilegível.

Se, como já se disse, "a cura pela arte consiste na capacidade de dar uma forma à própria enfermidade" (Moisés, 2001, p. 318), é interessante anotar as elaborações de Lacan sobre o modo como a arte do escritor de Um retrato do artista quando jovem lhe permitiu dar uma forma ao corpo, diferente daquela de "uma 
casca madura e macia despojada do seu fruto" (Joyce, 2006, p. 93). Se o parlêtre, ${ }^{8} \mathrm{o}$ falasser, encontra sua única consistência no seu corpo, no sentimento de que o tem, apesar de ele lhe escapar todo o tempo, esse corpo, enraizado no imaginário, e o amor-próprio que pode lhe estar associado (Lacan, 1975-76, p. 6364), é objeto de um desligamento no caso de Joyce e será, de algum modo, religado através da sua arte, também dita "escritura do ego" (ibid., p. 139-151). Assim, a arte cumpre aí uma função especificada de modo provocativo: "mas como ele tinha o pau um pouco mole foi sua arte que supriu sua firmeza fálica. (...) E é nisso que sua arte é o verdadeiro fiador de seu falo" (ibid., p. 16).

Se, com Joyce, é à arte que caberá essa função de avalizar ali onde algo não se aguenta de pé, ou de suprir ali onde algo não se amarra bem, no texto "A terceira" os fiadores do falo são os gadgets produzidos pela ciência. Lacan (1974-75) menciona, nesse sentido, o automóvel que pode ser tomado como uma falsa mulher. No entanto, nesse último texto o falo é apresentado como aquilo que nos impede de ter uma relação com algo que seria o nosso fiador sexual, pois "ele é nosso fiador para-sexuado, e todos sabem que o 'para' consiste em que cada um fique do seu lado, que cada um fique ao lado do outro" (s/p). De algum modo, tanto a arte quanto os gadgets poderiam ser pensados a partir do estatuto de fiadores "parasexuados" com os quais o sujeito estabelece parcerias sintomáticas, ou melhor, sinthomáticas. Seriam esses fiadores para-sexuados algo como uma espécie de pharmakon, isto é, eles remediariam a inoperância paterna sem, no entanto, poderem fazer vigorar o "não há" da relação sexual? Ao aproximar-se dos gadgets, a arte estaria afastada do seu caráter sublimatório? Afastada a ponto de perdê-lo de vista, ou não? Essas são questões que abrem para novas elaborações.

\section{Referências}

Aflalo, A. Os nove pontos de Agnes. In: Os casos raros, inclassificáveis da clínica psicanalítica. A conversação de Arcachon. São Paulo: Biblioteca Freudiana Brasileira, 1998. p. 107-109.

DSM-IV-TRTM. Transtorno dismórfico corporal. In: Manual diagnóstico e estatísti-

8. No termo parlêtre, Lacan condensa a forma verbal "parle" (terceira pessoa do presente do indicativo) e o verbo "être", infinitivo e substantivo. Ao transformar o l'être parlant (o ser falante) em parlêtre, falasser, fica sugerida uma espécie de ocultação do ser no ato da palavra. (Nota extraída de Actas de la Escuela Freudiana de Paris. Barcelona: Petrel, 1980. p. 178). 
co de transtornos mentais. Trad. de Claudia Dornelles. 4. ed. ver. Porto Alegre: Artmed, 2002. p. 488-491.

Frege, G. (1892). Sobre o sentido e a referência. In: Lógica e filosofia da linguagem. São Paulo: Cultrix, 1978.

Freud, S. (1917). O sentido dos sintomas e Os caminhos da formação dos sintomas. Conferências introdutórias sobre a psicanálise. In: Edição Standard Brasileira das Obras Psicológicas Completas de Sigmund Freud. Rio de Janeiro: Imago, 1976. v. XVI, p. 305-322; p.419-439.

Joyce, J. A Portrait of the Artist as a Young Man. Text, Criticism, and Notes by Chester G. Anderson. New York: Penguin Books, 1977. . (1916). Um retrato do artista quando jovem. Trad. de Bernardina Silveira Pinheiro. Rio de Janeiro: Objetiva, 2006.

LaCan, J. (1955-56). O seminário. Livro III. As psicoses. Rio de Janeiro: Jorge Zahar, 1985.

. (1955-56). De uma questão preliminar a todo tratamento possível da psicose. In: Escritos. Rio de Janeiro: Jorge Zahar, 1998. p. 537-590.

. (1966). De nossos antecedentes. In: Escritos. Rio de Janeiro: Jorge Zahar, 1998. p. 69-76.

. (1974). La troisieme. Lettres de L'École Freudienne, Paris, n. 16, s/p, 1975. . (4.10.1975). Conference a Geneve sur le symptome. Le Bloc-notes de la Psychanalyse, Paris, n. 5, s/p, 1985.

. (24.11.1975). Conférences et entretiens dans des universités nordaméricaines (Yale University). Scilicet, Paris, n. 6/7, p. 7-41, 1975; Paris: Seuil, 1976.

. (1975a). Uma psicose lacaniana: entrevista conduzida por Jacques Lacan. Opção Lacaniana, São Paulo, n. 26/27, p. 5-16, abr. 2000.

. (1975b). Joyce, o sintoma. In: Outros escritos. Rio de Janeiro: Jorge Zahar, 2003. p. 560-566. 2007.

. (1975-76). O seminário. Livro 23. O sinthoma. Rio de Janeiro: Jorge Zahar,

. (16.11.1976). L'insu que sait de l'une-bévue s'aile a mourre. Ornicar? Bulletin périodique du Champ freudien, Paris, n. 12/13, p. 5-9, Déc.1977.

Miller, J.-A. et al. (1997). Os casos raros, inclassificáveis da clínica psicanalítica. A Conversação de Arcachon. São Paulo: Biblioteca Freudiana Brasileira, 1998. . La psicosis ordinaria. Buenos Aires: Paidós, 2005. 
Miller, J.-A. A psicanálise e a psiquiatria. Falo, Salvador, n. 1, p. 113-124, jul. 1987.

. Introdução a um discurso do método analítico. Seminário do Campo Freudiano, Terceira Conferência, Falo, Salvador, n. 2, p. 87-96, jan.jun. 1988.

. Biología lacaniana e acontecimentos de corpo. Opção Lacaniana, São Paulo, n. 41. p. 7-67, dez. 2004.

MoIsés, L. P. Fernando Pessoa, aquém do eu, além do outro. São Paulo: Martins Fontes, 2001.

Rosa, M. Forclusão e fenômenos elementares. Curinga, Belo Horizonte, n. 14, p. 24-33, abr. 2000.

\section{Resumo}

(La psicosis ordinaria y los fenómenos de cuerpo)

Este artículo incorpora las formulaciones lacanianas de los años 1950 sobre la psicosis, psicosis freudiana a la Schreber, y aquellas otras de los años 1970, propuestas a partir del sinthoma joyciano, con el fin de debatir un nuevo nombre surgido contemporaneamente, la psicosis ordinaria, y la forma en que esta trata el cuerpo.

Palabras clave: Psicosis ordinaria, cuerpo, clinica estructural, clinica del sinthoma

(La psychose ordinaire et les phénomènes du corps)

Cet article reprend les formulations lacaniennes des années 1950 sur la psychose, la psychose freudienne à la Schreber, et celles d'autres des années '70, sur les propositions du Sinthome de Joyce afin de discuter l'apparition d'un nouveau terme, la psychose ordinaire, et de quelle façon elle traite le corps

Mots clés: Psychose ordinaire, corps, clinique structurelle, clinique du sinthome

(Ordinary psychosis and phenomena of the body)

This article discusses formulations made by Lacan during the 1950s on psychosis, Freudian psychosis à la Schreber, and other approaches taken during the 1970s, proposed on the basis of the concept of sinthome, coined especially in reference to James Joyce. The intent is to discuss a new category that has emerged recently, namely, ordinary psychosis, and how it treats the body.

Key words: Ordinary psychosis, body, structural blinic, clinic of the sinthome 
Citação/Citation: Rosa, M. A psicose ordinária e os fenômenos de corpo. Revista Latinoamericana de Psicopatologia Fundamental, São Paulo, v. 12, n. 1, p. 116-129, mar.2009.

Editor do artigo/Editor: Prof. Dr. Manoel Tosta Berlinck.

Recebido/Received: 13.8.2008 / 8.13.2008 Aceito/Accepted: 20.8.2008 / 8.20.2008

Copyright: (C) 2009 Associação Universitária de Pesquisa em Psicopatologia Fundamental/ University Association for Research in Fundamental Psychopathology. Este é um artigo de livre acesso, que permite uso irrestrito, distribuição e reprodução em qualquer meio, desde que o autor e a fonte sejam citados/This is an open-access article, which permits unrestricted use, distribution, and reproduction in any medium, provided the original author and source are credited.

Financiamento/Funding: $\mathrm{O}$ autor declarou não ter sido financiado ou apoiado/The author has no support or funding to report.

Conflito de interesses: $O$ autor declararou que não há conflito de interesses/The author declares that has no conflict of interest.

\section{Márcia Rosa}

Psicóloga; psicanalista; membro da Escola Brasileira de Psicanálise e da Associação Mundial de Psicanálise; doutora em Literatura Comparada (Universidade Federal de Minas Gerais -UFMG, Belo Horizonte, BH, Brasil); pós-doutorado em Teoria Psicanalítica (Universidade Federal do Rio de Janeiro - UFRJ, Rio de Janeiro, RJ, Brasil); coordenadora da Pós-Graduação lato-senso: "Psicanálise aplicada à saúde mental" (Centro Universitário do Leste de Minas Gerais - Unileste-MG, Coronel Fabriciano, MG, Brasil).

Rua Levindo Lopes, 333, sala 305 - Savassi

30140-170 Belo Horizonte, MG, Brasil

Fones: (31) 3296-9423; 3281-0708; 9617-6443

e-mail: marcia.rosa@globo.com 